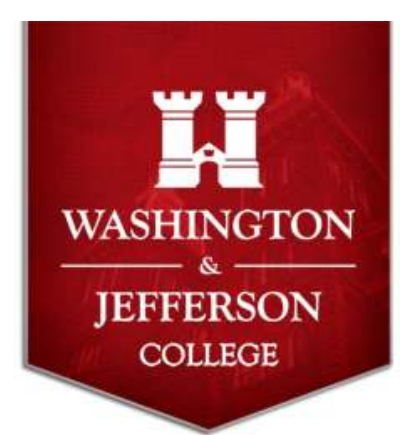

\title{
Bridge course between Organic Chemistry I and II
}

Michael S. Leonard

Department of Chemistry, Washington \& Jefferson College

60 South Lincoln Street

Washington, PA 15301

Abstract

A course intended to ease the transition from Organic Chemistry I to II was designed for a twoweek January term that features sharply focused topics courses. The goal is to facilitate student
success in the inherently cumulative yearlong Organic Chemistry sequence. Key topics from Organic Chemistry I are revisited (e.g. spectroscopy, substitution/elimination) to ensure that students have the Iroper foundation to proceed. Then, a selection of Organic Chemistry 11 material is introduced. The course focuses heavily on interactive problem solving and utilizes an open-
access text written by the instructor. YouTube videos created by the instructor also support access text writt.
student learning.

Introduction

Washington \& Jefferson (W\&) College is a private liberal arts and sciences college south of

enrollment of approximately 1400 a total

enrollment of approximately 1,400 students.
The W\&] chemistry department offers both chemistry and American Chemical Society-
approved majors, and graduates of the College

earn a Bachelor of Arts degree.

The curriculum features an organic-first approach. The first-year sequence, Organic Chemistry Structure and Fundamentals followed by Organic Chemistry - Reactions and Synthesis, utilizes a $1-7$ of the textbook with the spectroscopy chapter incorporated into covers chap
laboratory.

Table 1. Topics Covered in Organic Chemistry - Structure and Fundamentals

\begin{tabular}{|c|c|}
\hline Chapter & Introduction to Organic Chemistry \\
\hline 1 & Acid-Base Chemistry \\
\hline 2 & Alkanes \\
\hline 3 & Stereochemistry \\
\hline 4 & Infrared Spectroscopy and Nuclear Magnetic Resonance Spectroscopy \\
Radical Reactions \\
\hline 7 & Substitution and Elimination - Reactions of Alkyl Halides and Alcohols \\
\hline 7 & Thes \\
\hline
\end{tabular}
The second-semester class continues with a typical study of functional groups and their reactivity.

Table 2. Topics Covered in Organic Chemistry - Reactions and Synthesis

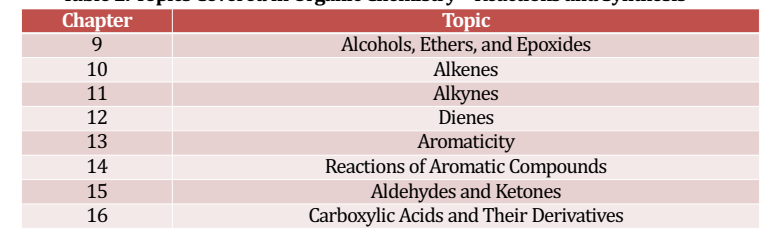

As a result of redesigning the academic calendar at W\&, there is a two-week window during the month of January called JayTerm in which sharply focused, two-credit topics courses may be
offered. This reimagined January session provided a vehicle for a new chemistry class, an elective bridge course called "Easing the transition from Organic Chemistry I to II"

Course Design

The bridge course has two prerequisites. Students should have completed Organic Chemistry Structure and Fundamentals and be enrolled in Organic Chemistry - Reactions and Synthesis for
the subsequent spring semester. The bridge course meets for two and a half hours five days a week for the duration of JayTerm (a total of 10 class periods and 25 hours of meeting time). The course
has three principal goals: to review key topics from Structure and Fundamentals, to introduce a representative selection of moterial from Reacions and Synthesis and to use intective poble solving as the main form of pedagogy. A week was set aside for review, and a week was devoted to Solving as the main form of pedagogy. A week was set aside for review
introducing the major concepts of the Reactions and Synthesis course.
Table 3. Topics by Day of Class

\begin{tabular}{|c|c|c|c|}
\hline & Day & Chapter(s) & Topic(s) \\
\hline \multirow{5}{*}{ Week 1} & Monday & $1-3$ & Introductory material, acids \& bases, alkanes \\
\hline & Tuesday & 4 and 5 & Stereochemistry and spectroscopy \\
\hline & Wednesday & 5 and 6 & Spectroscopy and radicals \\
\hline & Thursday & 7 & Substitution and elimination \\
\hline & Friday & -- & Exam 1 \\
\hline \multirow{5}{*}{ Week 2} & Monday & 9 & Alcohols, ethers, and epoxides \\
\hline & Tuesday & $10-12$ & Alkenes, alkynes, dienes \\
\hline & Wednesday & 13 and 14 & Aromatic compounds \\
\hline & Thursday & 15 and 16 & Aldehydes, ketones, and carboxylic acids derivatives \\
\hline & Friday & & Exam II \\
\hline
\end{tabular}

For the first three days, students are asked to review their notes from Structure and Fundamentals. Once the topics take a mechanistic turn, students are asked to watch a selection o

Table 4. YouTube Video Pre-Class Assignments

\begin{tabular}{|c|c|c|c|}
\hline \multirow{6}{*}{ Week 1} & \multicolumn{2}{|r|}{ YouTube Video Assignment(s) } & \multirow{6}{*}{$\begin{array}{l}\text { Bridge-course students outperformed their coun } \\
\text { margin but sometimes by a wide margin (ifigure } \\
\text { performed in between or higher than their peers } \\
\text { average Reactions and Synthesis grade that was } 2 \\
\text { often see a decline in scores over the two-seme } \\
\text { nature of the material. However, the bridge-co } \\
\text { percentage points less than their peers in the com }\end{array}$} \\
\hline & \multirow{5}{*}{ Thursday } & SN1 reaction & \\
\hline & & SN2 reaction & \\
\hline & & E1 reaction & \\
\hline & & E2 reaction & \\
\hline & & Deciding Between SN1, SN2, E1, and E2 Pathways & \\
\hline & & Reaction of Alcohols with $\mathrm{HX}$ & \\
\hline & & Reaction of Alcohols with Phosphorus Tribromide & . \\
\hline & Monday & Reaction of Alcohols with Thionyl Chloride & . \\
\hline & & Dehydration of Alcohols & \\
\hline & & Williamson Ether Synthesis & ... \\
\hline & & Ionic Hydrohalogenation of Alkenes & \\
\hline & & Acid-Catalyzed Hydration of Alkenes & \\
\hline & & Oxymercuration-Demercuration & \\
\hline & Tuesday & Hydroboration-Oxidation & 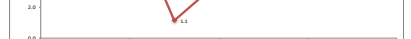 \\
\hline & & Halogenation of Alkenes & \\
\hline
\end{tabular}
Week 2 Conjugated Dienes Wednesday Electrophilic Aromatic Substitution: Nitration Electrophilic Aromatic Substitution: Sulfonation Friedel-Crafts Alkylation Friedel-Crafts Acylation Hydrate Formation Acetal Formation and Hydrolysis mine Formation and Hydrolysis Enamine Formation and Hydrolysis

Thursday _ Nucleophilic Acyl Substitution of Acid Chlori Nucleophilic Acyl Substitution of Esters (focus on basic hydrolysis, aka saponification ucleophilic Acyl Substitution of Carboxylic Acids ffocus on Fischer Esterification)

These videos ${ }^{2}$ employ the same color-coded approach to mechanism as the textbook. ${ }^{1}$ The strategy is to color code identically the electrons in a bond or unshared pair, the arrow emanating
from that site, and the electrons in the incipient bond or unshared pair. An example is provided in Figure 1 for an SN1 reaction involving a carbocation rearrangement.
Figure 2. Difference in Reactions and Synthesis exam grades ( $\diamond$ between studen triad that did not.

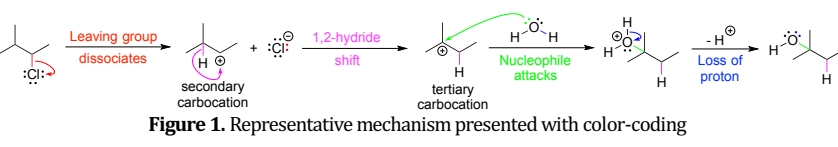
The focus of each day's class is a worksheet. Students work on one problem at a time using the think, pair, square, share method. To incentivize robust engagement, participation accounts for
$25 \%$ of the course grade. A homework set is distributed at the end of each class. Homework is $25 \%$ of the overall grade and is checked for completion but not correctness. The remainder of the final grade apiece. Exams are taken independently as is traditional and therefore gauge each technical capability.

Assessment

Student triads were studied. Each triad included a student who took the bridge course as well as

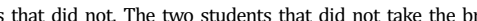
because their grades in Structure and Fundamentals bracketed that of the bridge-course student.
Performance of the triads was followed through Reactions and Synthesis

Bridge-course students outperformed their counterparts on every exam, sometimes by a narrow (

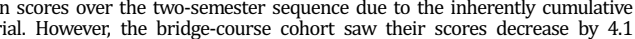

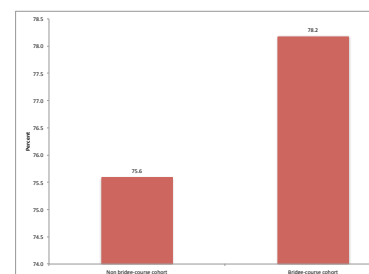

Figure 4. Average Reactions and Synthesis grade.

References

1. Textbook \& Solutions Manual: Figure 3. Percentage of bridge-course

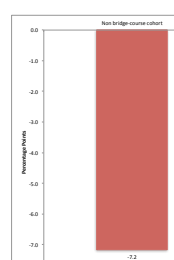

Figure 5. Change in score from Structure and Fundamentals to Reactions and Synthesis.

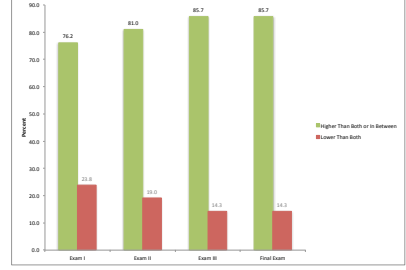

